\title{
Interactions between the entomopathogenic fungus Beauveria bassiana and the Neotropical predator Eriopis connexa (Coleoptera: Coccinellidae): Implications in biological control of pest
}

\author{
Ana Clara Scorsetti ${ }^{1 *}$, Sebastian Pelizza ${ }^{2}$, Marilina Noelia Fogel ${ }^{3}$, \\ Florencia Vianna ${ }^{1}$, Marcela Ines Schneider ${ }^{3}$ \\ ${ }^{1}$ Botanical Institute Carlos Spegazzini (FCNyM-UNLP), Calle 53\#477, 1900 La Plata, Buenos Aires, Argentina \\ ${ }^{2}$ Centre of Parasitological and Vector Studies (CEPAVE), CCT La Plata-CONICET-UNLP, \\ Boulevard 120 s/n between 61 and 64, 1900 La Plata, Buenos Aires, Argentina \\ ${ }^{3}$ Laboratory of Ecotoxicology: Pesticides and Biological Control, Centre of Parasitological and Vector Studies \\ (CEPAVE-CONICET-UNLP), Boulevard 120 s/n between 61 and 64, 1900 La Plata, Buenos Aires, Argentina
}

Vol. 57, No. 4: 389-395, 2017

DOI: 10.1515/jppr-2017-0053

Received: August 23, 2017

Accepted: November 15, 2017

*Corresponding address:

ascorsetti@conicet.gov.ar

\begin{abstract}
Aphids (Hemiptera: Aphididae) are serious pests of crops causing direct damage by feeding and indirect by the transmission of plant viruses. The use of conventional insecticides for controlling aphids has caused different problems and insecticide resistance. Accordingly, there is more interest in alternative control methods such as biological control by natural enemies for sustainable agricultural management. Among biological control agents, entomopathogenic fungi are one of the most significant microbial pathogens of insects. Also, Coccinellidae, as a major group, is a serious natural enemy. Both larval and adult stages of Coccinellidae feed on different soft-body pests, such as aphids. Eriopis connexa (Germar) (Coleoptera: Coccinellidae) is a common species in agroecosystems of the Neotropical region where it is considered to be a potential control agent. Pathogens and arthropod natural enemies may contribute to the control of phytophagous pests; however, it is important to assess potential interactions within biological control agents that share hosts (intraguild interaction) to evaluate their combined use for pest control. Therefore, the aim of this study was to evaluate the compatibility and interaction (lethal and sublethal effects) between E. connexa and the entomopathogenic fungus Beauveria bassiana (Bals.-Criv.) Vuill. (Ascomycota: Hypocreales). Both are important biological control agents of aphids. The pathogenicity of B. bassiana against larvae, pupae and adults of the predator E. connexa was evaluated, and results showed, that B. bassiana infected the coleopteran. On the other hand, interaction between B. bassiana and the predator was evaluated through infected-prey. The effects of fungus on larvae survival were significantly different when we analyzed the accumulated survival (from first larval instar to adulthood). The daily fecundity was significantly reduced at five days compared to control group. By contrast, no significant differences were observed between the five oviposition days in the rate of hatched eggs. This study shows that despite having received a single dose of the fungus in its life cycle, the population parameters of the predator E. connexa are affected. More studies would be necessary to help identify interactions between microbes and natural enemies to increase and enhance opportunities and further develop biological pest control programs.
\end{abstract}

Key words: Beauveria bassiana, biological control, Eriopis connexa, pathogen-predator interaction 


\section{Introduction}

Aphids (Hemiptera: Aphididae) are serious pests in agricultural and horticultural crops through direct damage by feeding and indirect by the transmission of more than 300 plant viruses (Hogenhout et al. 2008). The use of conventional insecticides for controlling aphids has caused different problems (e.g. failures in pest control and negative environmental impact) and insecticide resistance by aphids (Foster et al. 2007). Therefore, in recent years there has been more interest in other control methods such as biological control by natural enemies for sustainable agricultural management (Lacey et al. 2015). Among biological control agents, fungi are one of the most significant microbe pathogens of insects. At least 16 species of fungi are known to infect aphids in nature, and several species frequently cause epizootics among aphid populations (Pell et al. 2001; Chen et al. 2008). In Argentina, several fungal species associated with aphid pests of horticultural crops were cited: Conidiobolus obscurus (Hall \& Dunn) Remaudière \& Keller, Entomophthora planchoniana Cornu, Neozygites fresenii (Nowakowski) Remaudière \& Keller, Pandora neoaphidis (Remaudière \& Hennebert) Humber and Zoophthora radicans (Brefeld) Batko (Entomophthoromycotina: Entomophthorales) (Scorsetti et al. 2007) and Lecanicillium lecanii (Zimmerm.) Zare \& W. Gams, L. longisporum (Petch) Zare \& Gams, L. muscarium (Petch) Zare \& W. Gams (Ascomycota: Hypocreales) (Scorsetti et al. 2010, 2012).

Mitosporic entomopathogenic fungi in the order Hypocreales, such as Beauveria bassiana (Bals.-Criv.) Vuill., L. longisporum and Isaria fumosorosea Wize, have been successfully utilized as biological control agents against numerous pests including aphids (de Faria and Wraight 2007; Powell and Pell 2007; Draganova et al. 2008). The main biological attributes for a mycoinsecticide are the virulence toward the target insect and that it is not harmful to other beneficial organisms such as parasitoids and predators (Riddick et al. 2009).

Coccinellidae make up a major group of natural enemies both the larval and adult stages of this predator species feed on different soft-body pests, such as aphids, whiteflies, mites and mealybugs (Biddinger et al. 2009; Obrycki et al. 2009). Eriopis connexa (Germar) (Coleoptera: Coccinellidae) is a common species in agroecosystems of the Neotropical region where it is considered to be a potential control agent (Sarmento et al. 2007; Duarte Gómez and Zenner de Polanía 2009). In Argentina, this species is commonly associated with key horticultural pests such as Myzus persicae (Sulzer, 1776), Aphis gossypii Glover 1877 (Hemiptera: Aphididae) and Bemisia tabaci (Gennadius, 1889) (Hemiptera: Aleyrodidae) (Fogel 2012).

Pathogens and arthropod natural enemies may contribute to the control of phytophagous pest populations in biological control programs. However, it is important to assess potential interactions between biological control agents that share the same host (intraguild interaction) to evaluate their combined use for pest control. It is well documented that several species of natural enemies may interact synergistically, additively or antagonistically to each other. While a synergistic or additive interaction could accelerate the reduction of insect pest populations, an antagonistic response could interact negatively in controlling insect pests (Roy and Pell 2000).

Intraguild interaction and compatibility between entomopathogenic fungi and other biological control agents of pests have been studied more with parasitoids than predators (Mesquita and Lacey 2001; Rashky et al. 2009; Jarrahi and Safavi 2016). In recent studies Mohamed and Hatcher (2017) have reported that the parasitoid Aphidius colemani (Dalman, 1820) (Hymenoptera: Braconidae) and L. muscarium could be used together for $M$. persicae control. Likewise, B. bassiana and Metarhizium brunneum Petch (Ascomycota: Hypocreales) results were compatible with A. colemani without any negative intraguild interaction between them (Jaber and Araj 2017).

Steenberg and Harding (2009) reported entomopathogenic fungi isolated from the harlequin ladybird predator Harmonia axyridis (Palls) (Coleoptera: Coccinellidae) from field samples and observed that the larval stage was the most susceptible to fungal infection, through bioassays with the entomopathogenic fungus Isaria farinosa (Holmsk.) (Ascomycota: Hypocreales). In contrast, Bayissa et al. (2016) demonstrated that the compatibility between Metarhizium anisopliae (Metchnikoff) Sorokin (1883) (Ascomycota: Hypocreales) and the predator Cheilomenes lunata (Fabricius) (Coleoptera: Coccinellidae), could provide a sustainable strategy for effective management of aphids on crucifers.

Most studies are focused on the interaction between parasitoids and pathogens. However, there have been few studies on predators. Therefore, the aim of this study was to evaluate the compatibility and interaction (lethal and sublethal effects) between the predator E. connexa and the entomopathogenic fungus B. bassiana, both, important biological control agents of aphids.

\section{Materials and Methods}

\section{Fungal culture}

The strain B. bassiana LPSc 1067, from the culture collection of the Spegazzini Institute, La Plata, Argentina was chosen based on its laboratory efficacy against several insect pests (Pelizza et al. 2012). It was identified 
using both molecular and morphological data Gen-Bank (accession number KF500409).

Conidia were obtained from a culture on potato dextrose agar (PDA, Britania S.A., Buenos Aires, Argentina) maintained for 10 days at $25^{\circ} \mathrm{C}$ in darkness. Conidia were harvested by a cell scraper (Fisherbrand $\left.{ }^{\circ}\right)$ and placed in Tween ${ }^{\circledR} 80$ (sodium polysorbate) $0.01 \%$ $(\mathrm{v} / \mathrm{v})$. Suspensions were adjusted to $1 \times 10^{7}$ conidia $\cdot \mathrm{ml}^{-1}$ by a Neubauer hemocytometer. Conidial viability was determined before each stock suspension was prepared by spreading $0.2 \mathrm{ml}$ of a $1 \times 10^{4}$ conidia $\cdot \mathrm{ml}^{-1}$ suspension on a slide with PDA and estimating the number of germinated propagules after $24 \mathrm{~h}$ at $25^{\circ} \mathrm{C}$. Propagules were considered viable when the germ tube length was equal to or longer than the spore diameter when observed under a phase contrast microscope at $400 \times$ magnification (Goettel and Inglis 1997).

\section{Insect rearing}

The coccinellid E. connexa was obtained from organic horticultural crops in the nearest La Plata city, Buenos Aires province, Argentina ( $34^{\circ} 57^{\prime} 17^{\prime \prime} \mathrm{S}, 57^{\circ} 53^{\prime} 26^{\prime \prime} \mathrm{W}$ ). Insects were kept isolated inside an incubator chamber to avoid the presence of pathogens from the field. Insects used in the bioassays were after the second generation. Adults were kept in polycarbonate cages $(14.5 \times 14 \mathrm{~cm})$ covered with a fine mesh. Eggs were removed and placed in plastic Petri dishes. Larvae were reared in plastic Petri dishes until pupation. Insects were maintained in a rearing room under controlled conditions $\left[25 \pm 2{ }^{\circ} \mathrm{C}, 70 \pm 5 \%\right.$ relative humidity (RH) and $16: 8 \mathrm{~h} \mathrm{~L}: \mathrm{D}]$.

The aphid Rhopalosiphum padi L. (Hemiptera: Aphididae) was used as prey. Aphid colonies were initiated with clones supplied by the technical personnel of the Faculty of Agricultural and Forestry Sciences (National University of La Plata), and were reared on wheat Triticum aestivum L. (cultivar Klein Capricornio, Cauda Semillas, Chacabuco, Argentina). Wheat seeds were pre-germinated and planted in a sterilized vermiculite : soil : perlite substrate mix $(1: 1: 1)$. Seedlings were aphid infected and maintained in ventilated cages under the same controlled conditions as the predator. Larvae and adults of predator were also feed with a supplement of honey, water and pollen mixture.

\section{Bioassay 1: Pathogenicity test}

The pathogenicity of $B$. bassiana against larvae, pupae and adults of the predator E. connexa was evaluated by aspersion technique. Treated insects were sprayed with $300 \mu \mathrm{l}$ of a conidial suspension of $1 \times 10^{7} \mathrm{conidia} \cdot \mathrm{ml}^{-1}$, with a $35-\mathrm{ml}$ glass atomizer, while the control insects were sprayed with $300 \mu \mathrm{l}$ of $0.01 \%(\mathrm{v} / \mathrm{v})$ Tween ${ }^{\circledR} 80 \mathrm{co}$ nidia-free. The experiment consisted of three replicate test groups and three control groups, with all groups containing 10 insects each. Adults used in assays were $10-15$ days old.

Insects were treated and placed in a Petri dish with sterile filter paper to dry excess inoculum. Then, they were settled individually in Petri dishes and fed ad libitum with R. padi aphid as prey. The cumulative mortality was recorded daily for 10 days. Dead insects were surface sterilized and placed in a humidity chamber to allow fungal infection according to Lacey and Brooks (1997). Dead insects were observed until visual signs of mycosis appeared or for 14 days after treatment. The experiments were repeated three times under comparable laboratory conditions. All the bioassays were carried out in a growth chamber with controlled environmental conditions $\left(25 \pm 2^{\circ} \mathrm{C}, 70 \pm 5 \% \mathrm{RH}\right.$ and $16: 8 \mathrm{~h} \mathrm{~L}: \mathrm{D})$.

\section{Bioassay 2: Interaction through prey. Larval survival, development, fecundity and fertility}

Interaction between the entomopathogenic fungus B. bassiana and the predator was evaluated through infected-prey. For the treatment, aphids were sprayed with a $B$. bassiana suspension of $1 \times 10^{7}$ conidia $\cdot \mathrm{ml}^{-1}$ $0.01 \%(\mathrm{v} / \mathrm{v})$ Tween ${ }^{\circledR} 80$, and placed in a Petri dish with sterile filter paper to dry excess inoculum. Control aphids were applied with $0.01 \%(\mathrm{v} / \mathrm{v}) \mathrm{Tween}^{\circledR} 80$ conidia-free.

First larval instar ( $24 \mathrm{~h}$ post-hatched and starved) of E. connexa were placed individually in Petri dishes $(90 \mathrm{~mm})$ and were provided with 25 infected-aphids. When all infected aphids had been eaten, each larva was fed ad libitum with healthy $R$. padi aphid. The experiment consisted of three replicate test groups and three control groups, with all groups containing 10 insects each. Survival and development time of immature stages (from larva to pupa) were checked, every $24 \mathrm{~h}$ until adult emergence.

Sublethal effects on fecundity and fertility were assessed on adults emerged from treated and control larvae. Newly emerged adults, both males and females, were placed in plastic cylindrical containers $(14 \mathrm{~cm}$ diameter and $14.5 \mathrm{~cm}$ high) and $R$. padi aphids were provided ad libitum. After five days, ten mated females per treatment were randomly selected for the reproduction assessment. Females were placed individually in plastic glasses ( $5 \mathrm{~cm}$ diameter and $10 \mathrm{~cm}$ high) with a fine mesh net fixed to the upper opening to allow ventilation. The inner walls of the containers were previously covered with paper as substrate for the oviposition, and R. padi aphids were offered ad libitum. During the following five days, egg batches were registered and counted daily (Fogel et al. 2013). Newly laid eggs were collected and individualized placed individually in Petri dishes. Fecundity (number of laid eggs) and fertility (number of hatched eggs) were recorded for each female. 
Insects were maintained in a growth chamber under controlled conditions $\left(25 \pm 2^{\circ} \mathrm{C}, 70 \pm 5 \% \mathrm{RH}\right.$ and $16: 8 \mathrm{~h} \mathrm{~L}: \mathrm{D})$. The experiments were repeated two times under comparable laboratory conditions.

\section{Statistical analyses}

Before data analysis, the Shapiro-Wilk test was used to assess data normality. If the assumptions of ANOVA were not met, datasets were transformed $\left(\operatorname{arcsine} V_{\mathrm{x}}\right.$ ) or a non-parametric test for analysis of data was performed (Kruskal-Wallis test, with the bilateral Dunn test for multiple comparisons in pairs).

The parametric test of analysis of variance (ANOVA) and a posteriori Tukey test were used to analyze pathogenicity test data. Repeated measures ANOVA were done to analyze fecundity and fertility data of E. connexa adults. Means were separated by the LSD multiple range test among the tested doses $(\mathrm{p}<0.05)$. All the analyses were performed using the program XLSTAT (Addinsoft XLSTAT for Excel, Paris, France, 2009).

\section{Results}

\section{Pathogenicity test by direct spray on predator}

Bioassays of pathogenicity tests conducted with E. connexa showed that after 10 days, B. bassiana LPSc 1067 infected the coleopteran. There were significant differences between different instar evaluated $(F=22.02$; $\mathrm{df}=5 ; \mathrm{p}<0.001)$. The most susceptible stage was first larval instar, with a $38.8 \pm 3.51 \%$ of mortality, and the lowest mortality was recorded in pupal stage with $2.22 \pm 1.47 \%$ (Fig. 1). The average viability of the conidia was over $95 \%$. Fungal growth and sporulation of the fungal isolate was determined on the dead insects following the technique cited by Lacey and Brooks (1997).

\section{Interaction through infected prey}

The effects of $B$. bassiana through infected prey on E. connexa larvae survival were significantly different when we analyzed the accumulated survival (from first larval instar to adulthood) $(\mathrm{K}=3.84 ; \mathrm{p}=0.029)$, but, there were no significant differences in the survival of each individual stage (Table 1 ).

For the development time (days), statistical analysis showed that there were no significant differences from first larval instar to pupae $(\mathrm{K}=3.84 ; \mathrm{p}=0.092)$ being recorded over a total period of 14.8 and 14.9 days in treated and control groups, respectively. However, significant differences were observed in development time in first larval instar $(\mathrm{K}=3.84 ; \mathrm{p}=0.037)$, fourth

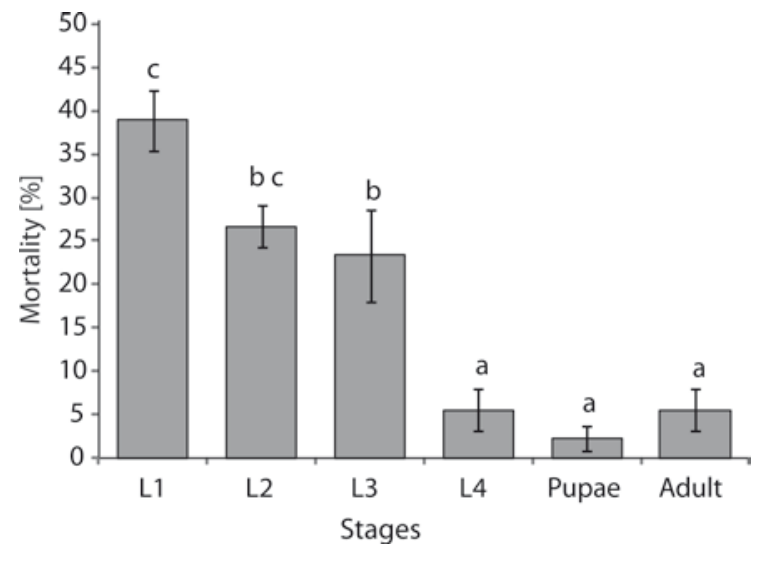

Fig. 1. Mean percent \pm SD mortality of Eriopis connexa exposed to Beauveria bassiana LPSc 1067 by pathogenicity test. The bars indicate standard errors, and different letters denote significant differences between stages according to the Tukey test $(p \leq 0.05)$

larval instar $(\mathrm{K}=3.84 ; \mathrm{p}<0.0001)$ and pupae $(\mathrm{K}=3.84$; $\mathrm{p}=0.019$ ) between treated and control groups (Fig. 2).

Effects of $B$. bassiana, through infected prey, on reproduction of E. connexa were assessed on those adults that emerged from treated and control groups. Effects on fecundity and fertility were evaluated according to time factor, for five consecutive days after first oviposition. When analyzing data according to time factor, an increasing tendency in fecundity after the first oviposition day was observed. The daily fecundity was significantly reduced at five days compared to control group $(\mathrm{F}=39.96 ; \mathrm{p} \leq 0.0001 ; \mathrm{df}=1,185)$. A mean number of 16.78 against 6.44 eggs/female were laid by control and treated E. connexa, respectively (Fig. 3). By contrast, no significant differences in the rate of hatched eggs from treated and control groups were observed between the five oviposition days $(\mathrm{F}=0.145 ; \mathrm{p}=0.704$; $\mathrm{df}=1,101$ ), reaching values of $80.45 \%$ and $81.30 \%$ of treated and control eggs, respectively.

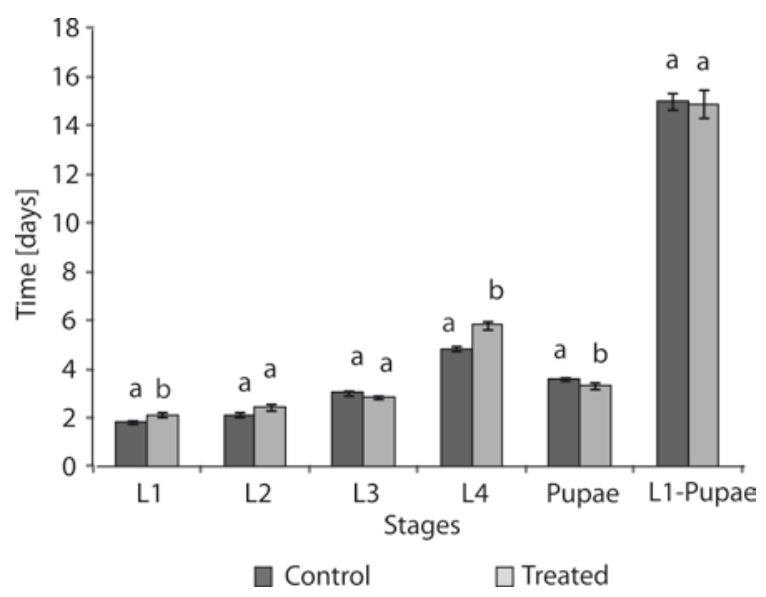

Fig. 2. Effects of Beauveria bassiana on the development time of immature stages of Eriopis connexa exposed to the fungus by ingestion (treated prey). The bars indicate standard errors, and different letters denote significant differences between treatments according to the Dunn test $(p \leq 0.05)$ 
Table 1. Effects on the survival of Beauveria bassiana through infected prey on immature stages and adults of Eriopis connexa

\begin{tabular}{lccccccr}
\hline \multirow{2}{*}{ Treatment } & $\mathrm{L} 1$ & $\mathrm{~L} 2$ & $\mathrm{~L} 3$ & $\mathrm{~L} 4$ & Pupae & Adults & Acumulated \\
& {$[\%]$} & {$[\%]$} & {$[\%]$} & {$[\%]$} & {$[\%]$} & $\begin{array}{r}\text { [\%] } \\
\text { survival* [\%] }\end{array}$ \\
\hline Control & $98.3 \pm 1.6 \mathrm{a}$ & $98.3 \pm 1.6 \mathrm{a}$ & $100 \pm 0 \mathrm{a}$ & $100 \pm 0 \mathrm{a}$ & $100.0 \pm 0 \mathrm{a}$ & $100 \pm 0 \mathrm{a}$ & $96.7 \pm 2.1 \mathrm{a}$ \\
Treated & $91.6 \pm 3.0 \mathrm{a}$ & $96.4 \pm 2.3 \mathrm{a}$ & $100 \pm 0 \mathrm{a}$ & $97.9 \pm 2.0 \mathrm{a}$ & $98.1 \pm 1.8 \mathrm{a}$ & $93.9 \pm 4.2 \mathrm{a}$ & $80.0 \pm 5.7 \mathrm{~b}$ \\
\hline & $\mathrm{p}=0.083$ & $\mathrm{p}=0.46$ & $\mathrm{n} / \mathrm{o}$ & $\mathrm{p}=0.31$ & $\mathrm{p}=0.31$ & $\mathrm{p}=0.14$ & $\mathrm{p}=0.02$ \\
& $\mathrm{df}=1,12$ & $\mathrm{df}=1,12$ & $\mathrm{df}=1,12$ & $\mathrm{df}=1,12$ & $\mathrm{df}=1,12$ & $\mathrm{df}=1,12$ & $\mathrm{df}=1,12$ \\
& $\mathrm{~K}=3.84$ & $\mathrm{~K}=3.84$ & $\mathrm{~K}=3.84$ & $\mathrm{~K}=3.84$ & $\mathrm{~K}=3.84$ & $\mathrm{~K}=3.84$ & $\mathrm{~K}=3.84$ \\
\hline
\end{tabular}

The data correspond to means $( \pm S E)$. Treatments with different letters are significantly different. Kruskal-Wallis test $(p<0.05)$

*number of adults regarding initial number of Larvae 1 (L1)

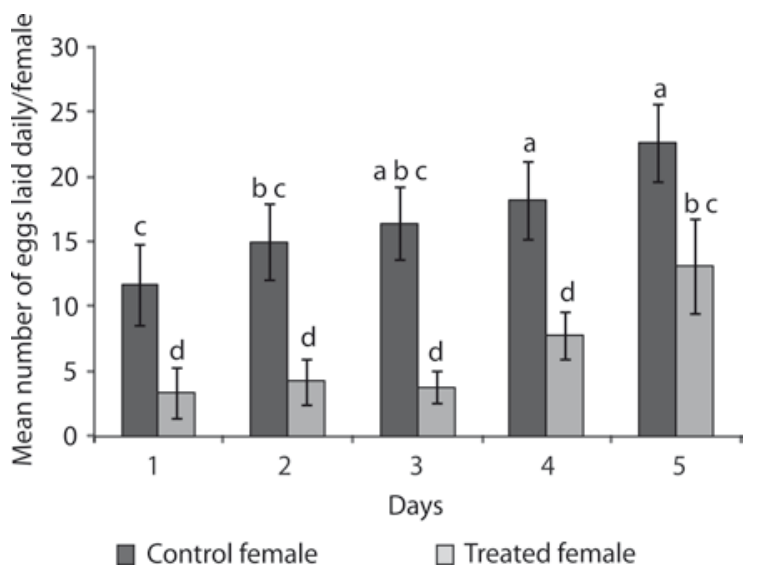

Fig. 3. Number of eggs laid daily by Eriopis connexa females from treated and control groups on five consecutive days. The bars indicate standard errors, and different letters denote significant differences between stages according to the Fisher (LSD) test $(p \leq 0.05)$

For personal observation, we recorded three E. connexa females that after the oviposition period died. They were conditioned in a humid chamber and the entomopathogenic fungus $B$. bassiana arose from the intersegmental zone of the body.

\section{Discussion}

Interspecific competition between natural enemy species is one of the most important factors determining biological control programs (Gonzalez et al. 2016). Studies about interactions between entomopathogenic fungi and other natural enemies (parasitoids and predators) have been performed worldwide (Roy et al. 2006; Ormond et al. 2011; Martins et al. 2014; Bayissa et al. 2016). However, there is very little information about interactions with other natural enemies in Coccinellidae species in general and E. connexa in particular.

Even though many coccinellid species and entompathogenic fungi may occupy the same spatial and temporal habitat, it is curious that so little information exists about the susceptibility and intraguild interactions between the predator species of Coccinellidae and entomopathogenic fungi.
A very small number of entomopathogenic fungi species have been isolated from coleopteran coccinellids collected under field conditions. The fungal species B. bassiana was isolated from Cycloneda sanguinea L. in Argentina (Toledo et al. 2008). The parasitic fungus Hesperomyces virescens (Laboulbeniales: Laboulbeniaceae) has been reported to infect several coccinellids, such as Chilocorus stigma Say, C. bipustulatus L., Adalia bipunctata (L.), H. axyridis, Hippodamia convergens Guérin-Méneville and E. connexa (Riddick et al. 2009). Even though this fungus invades the cuticle there are no known deleterious impacts on the host (Nalepa and Weir 2007). Cottrell and ShapiroIlan (2003) reported that field-collected Olla v-nigrum Mulsant was commonly found infected by B. bassiana, but $H$. axyridis was never found to be infected by this fungus, nor was mycosis exhibited after death.

Nevertheless, there are few studies about the pathogenicity of entomopathogenic fungi in laboratory bioassays. The present study represents the first study of pathogenicity and provides initial information about the interaction between the fungus B. bassiana and the predator E. connexa. Cottrell \& Shapiro-Ilan (2008) assayed the susceptibility of Olla v-nigrum, Coleomegilla maculata DeGeer, Cycloneda munda (Say, 1835) and $H$. convergens adults to B. bassiana isolates under laboratory conditions, showing $76 \%$ and $2 \%$ mortalities with a $\mathrm{LC}_{50}$ rate of $2.5 \times 10^{5}$ conidia $\cdot \mathrm{ml}^{-1}$. In our study, using a higher dose, adults were less susceptible after 10 days. The most susceptible stage was first larval instar and the lowest mortality was found in pupae stage. Also, Scorsetti et al. (2012) showed that the entomopathogenic fungus L. muscarium at a dose of $1 \times 10^{7}$ conidia $\cdot \mathrm{ml}^{-1}$ caused a mortality of $45 \pm 5 \%$ and $30 \pm 5 \%$ to L1 and L2 larval instar of E. connexa, respectively, under laboratory conditions.

Although laboratory-reared insects are more susceptible to pathogens (Hajek and Butler 2000), the ecological components and behavioral responses of the predators should be taken into consideration in order to explain the low or scarce incidence of entomopathogenic fungi infecting coccinellids under natural field conditions. Ormond et al. (2011) observed that both, male and female Coccinella septempunctata $\mathrm{L}$. 
avoided $B$. bassiana through contact with leaf surfaces, soil inoculated and mycosed cadavers. Also, Pell and Vandenberg (2002) demonstrated that the ladybird $H$. convergens avoided feeding on Russian wheat aphids, Diuraphis noxia Mordavilko, infected with I. fumosorosea. The ability of coccinellids to detect and avoid entomopathogenic fungi conidia is an adaptation that undoubtedly increases survival and ultimately fitness.

In this study, the method of inoculation to evaluate the sub-lethal effects was through fungus-infected prey aphids, offered one time only. Statistical analyses showed that there were no significant differences between the survivals of both treatments, inoculated and control groups, from larvae to adulthood. The development time (days) was 14.8 and 14.9 days in treated and control groups, respectively. Silva et al. (2013) found a total development period of 12.6 \pm 0.2 and $14.4 \pm 0.2$ days for treatment fed different aphids as prey, which is consistent with our study. However, significant differences were observed in development time in stages L1, L4 and pupae between treated and control groups. There were no differences observed on development time, nevertheless, the daily fecundity was significantly reduced at five days compared to control group. These results are consistent with a different study (Simelane et al. 2008) in which another coleopteran, C. septempunctata, reared on uninfected aphids produced significantly more eggs per day during the observation period than those reared on fungus-infected aphids. Also, 11\% of females reared on fungus-infected aphids oviposition stopped within a week and later died. Also, they found that both, male and female C. septempunctata reared on Neozygites fresenii - infected aphids were smaller than those reared on uninfected aphids.

This study shows that despite having received a single dose of fungus in its life cycle, the population parameters of predator E. connexa are affected.

Understanding the ecological consequences of using more than one biological control agent needs closer examination, especially for organic cropping systems that have evolved into complex ecosystems with populations of multiple arthropod natural enemy species. There are a limited number of studies involving microbes and arthropod natural enemies under field conditions. Thus, such studies would be necessary to help identify interactions between microbes and natural enemies to increase and enhance opportunities and further develop biological pest control programs.

\section{Acknowledgements}

This research was partially supported by Consejo Nacional de Investigaciones Científicas y Técnicas (PIP 0205) and Fondo para la Investigación Científica y Tecnológica (FONCYT; PICT 2013-0543).

\section{References}

Addinsoft. 2009. XLstat for Excel. Available on: https://www.xlstat.com/es/descargar [Accessed: July 20, 2009].

Bayissa W., Ekesia S., Mohameda S.A., Kaayab G.P., Wagachab J.M., Hannac R., Maniania N.K. 2016. Interactions among vegetable infesting aphids, the fungal pathogen Metarhizium anisopliae (Ascomycota: Hypocreales) and the predatory coccinellid Cheilomenes lunata (Coleoptera: Coccinellidae). Biocontrol Science and Technology 26 (2): 274-290. DOI: 10.1080/09583157.2015.1099148

Biddinger D.J., Weber D.C., Hull L.A. 2009. Coccinellidae as predators of mites: Stethorini in biological control. Biological Control 51 (2): 268-283. DOI: https://doi.org/10.1016/j. biocontrol.2009.05.014

Chen B., Li Z.Y., Feng M.G. 2008. Occurrence of entomopathogenic fungi in migratory alate aphids in Yunnan province of China. BioControl 53: 317-326.

Cottrell T.E., Shapiro-Ilan D.I. 2003. Susceptibility of a native and an exotic lady beetle (Coleoptera: Coccinellidae) to Beauveria bassiana. Journal of Invertebrate Pathology 84 (2): 137-144. DOI: https://doi.org/10.1016/j.jip.2003.09.003

Cottrell T.E., Shapiro-Ilan D.I. 2008. Susceptibility of endemic and exotic North American ladybirds (Coleoptera: Coccinellidae) to endemic fungal entomopathogens. European Journal of Entomology 105 (3): 455-460. DOI: 10.14411/ eje.2008.058

de Faria M.R., Wraight S.P. 2007. Mycoinsecticides and mycoacaricides: a comprehensive list with worldwide coverage and international classification of formulation types. Biological Control 43 (3): 237-256. DOI: https://doi.org/10.1016/j. biocontrol.2007.08.001

Draganova S., Donkova R., Georgieva D. 2008. Impact of strains of entomopathogenic fungi on some main groups of soil microorganisms. Journal of Plant Protection Research 48 (2): 169-179. DOI: https://doi.org/10.2478/v10045-008-0020-y

Duarte Gómez W., Zenner de Polanía I. 2009. Tabla de vida del cucarrón depredador Eriopis connexa (Germar). Revista U.D.C.A Actualidad \& Divulgación Científica 12: 147-155.

Fogel M.N. 2012. Selectividad de insecticidas utilizados en cultivos hortícolas del Cinturón Hortícola Platense sobre el depredador Eriopis connexa en el marco del Manejo Integrado de Plagas. P.Th. Doctoral, Facultad de Ciencias Exactas, Universidad Nacional de La Plata, Argentina, 146 pp.

Fogel M.N., Schneider M.I., Desneux N., Gonzalez B., Ronco A.E. 2013. Impact of the neonicotinoid acetamiprid on immature stages of the predator Eriopis connexa (Coleoptera: Coccinellidae). Ecotoxicology 22 (6): 1063-1071. DOI: 10.1007/s10646-013-1094-5

Foster S.P., Devine G., Devonshire A.L. 2007. Insecticide resistance. p. 261-278. In: "Aphids as Crop Pests" (H.F. Van Emden, R. Harrington, eds.). CAB International, London, UK, $716 \mathrm{pp}$.

Goettel M.S., Inglis G.D. 1997. Fungi: Hyphomycetes. p. 213-248. In: "Manual of Techniques in Insect Pathology" (L.A. Lacey, ed.). Academic Press, San Diego, USA.

Gonzalez F., Tkaczuk C., Dinu M.M., Fiedler Z., Vidal S., Zchori-Fein E., Messelink G.J. 2016. New opportunities for the integration of microorganisms into biological pest control systems in greenhouse crops. Journal of Pest Science 89 (2): 295-311. DOI: 10.1007/s10340-016-0751-x

Hajek A.E., Butler L. 2000. Predicting the host range of entomopathogenic fungi. p. 263-273. In: "Nontarget Effects of Biological Control” (P.A. Follett, J.J. Duan, eds.). Kluwer Academic Publisher, Dordrecht, NL.

Hogenhout S.A., Ammar E.D., Whitfield A.E., Redinbaugh M.G. 2008. Insect vector interactions with persistently transmitted viruses. Annual Review of Phytopathology 46: 327-359.

Jaber L.R., Araj S.E. 2017. Interactions among endophytic fungal entomopathogens (Ascomycota: Hypocreales), the green peach aphid Myzus persicae Sulzer (Homoptera: Aphidi- 
dae), and the aphid endoparasitoid Aphidius colemani Viereck (Hymenoptera: Braconidae). Biological Control. DOI: 10.1016/j.biocontrol.2017.04.005

Jarrahi A., Safavi S.E. 2016. Sublethal effects of Metarhizium anisopliae on life table parameters of Habrobracon hebetor parasitizing Helicoverpa armigera larvae at different time in tervals. BioControl 61 (2): 167-175. DOI 10.1007/s10526015-9707-y

Lacey L.A., Brooks W.M. 1997. Initial handling and diagnosis of diseased insects. p. 1-15. In: "Manual of Techniques in Insect Pathology" (L.A. Lacey, ed.). Academic Press, San Diego, USA.

Lacey L.A., Grzywacz D., Shapiro-Ilan D.I., Frutos R., Brownbridge M., Goettel M.S. 2015. Insect pathogens as biological control agents: Back to the future. Journal of Invertebrate Pathology 132: 1-41. DOI: 10.1016/j.jip.2015.07.009

Martins I.C.F., Silva R.J., Alencar J.R.D., Silva K.P., Cividanes F.J., Duarte R.T., Agostini L.T., Polanczyk C. 2014. Interactions between the entomopathogenic fungi Beauveria bassiana (Ascomycota: Hypocreales) and the aphid parasitoid Diaeretiella rapae (Hymenoptera: Braconidae) on Myzus persicae (Hemiptera: Aphididae). Journal of Economic Entomology 107 (3): 933-938. DOI: https://doi.org/10.1603/EC13542

Mesquita A.L.M., Lacey L.A. 2001. Interactions among the entomopathogenic fungus, Paecilomyces fumosoroseus (Deuteromycotina: Hyphomycetes), the parasitoid, Aphelinus asychis (Hymenoptera: Aphelinidae) and their aphid host. Biological Control 22 (1): 51-59. DOI: https://doi. org/10.1006/bcon.2001.0950

Mohammed A.A., Hatcher P.E. 2017. Combining entomopathogenic fungi and parasitoids to control the green peach aphid Myzus persicae. Biological Control 110: 44-55. DOI: http:// dx.doi.org/10.1016/j.biocontrol.2017.03.012

Nalepa C.A., Weir A. 2007. Infection of Harmonia axyridis (Coleoptera: Coccinellidae) by Hesperomyces virescens (Ascomycetes: Laboulbeniales): role of mating status and aggregation behavior. Journal of Invertebrate Pathology 94 (3): 196-203. DOI: 10.1016/j.jip.2006.11.002

Obrycki J.J., Harwood J.D., Kring T.J., O’Neil R.J. 2009. Aphidophagy by Coccinellidae: application of biological control in agroecosystems. Biological Control 51 (2): 244-254. DOI: https://doi.org/10.1016/j.biocontrol.2009.05.009

Ormond E., Thomas A.P.M., Pell J.K., Freeman S.N., Roy H.E. 2011. Avoidance of a generalist entomopathogenic fungus by the ladybird, Coccinella septempunctata. FEMS Microbiology Ecology 77: 229-237. DOI: 10.1111/j.1574-6941 2011.01100x

Pelizza S.A., Elíades L.A., Saparrat M.C.N., Cabello M.N., Scorsetti A.C., Lange C.E. 2012. Screening of argentine native fungal strains for biocontrol of the grasshopper Tropidacris collaris: relationship between fungal pathogenicity and chitinolytic enzyme activity. World Journal of Microbiology and Biotechnology 28 (4): 1359-1366. DOI: 10.1007/ s11274-011-0935-8

Pell J.K., Eilenberg J., Hajek A.E., Steinkraus D.C. 2001. Biology, ecology, and pest management potential of Entomophthorales. p. 71-153. In: "Fungal Biological Control Agents: Progress, Problems and Potential" (T.M. Butt, C. Jackson, N. Magan, eds.). CAB International. Wallingford, Oxon.

Pell J.K., Vandenberg J.D. 2002. Interactions among the aphid Diuraphis noxia, the entomopathogenic fungus Paecilomyces fumosoroseus and the coccinellid Hippodamia convergens. Biocontrol Science and Technology 12 (2): 217-224. DOI: http://dx.doi.org/10.1080/09583150120124478
Powell W., Pell J.K. 2007. Biological Control. p. 469-513. In: "Aphids as Crop Pests" (R. Harrington, H. van Emden, eds.). CABI International, $717 \mathrm{pp}$.

Rashki M., Kharazi-pakdel A., Allahyari H., van Alphen J.J.M. 2009. Interactions among the entomopathogenic fungus, Beauveria bassiana (Ascomycota: Hypocreales), the parasitoid, Aphidius matricariae (Hymenoptera: Braconidae), and its host, Myzus persicae (Homoptera: Aphididae). Biological Control 50 (3): 324-328. DOI: https://doi.org/10.1016/j. biocontrol.2009.04.016

Riddick E.W., Cottrell T.E., Kidd K.A. 2009. Natural enemies of the Coccinellidae: Parasites, pathogens, and parasitoids. Biological Control 51 (2): 306-312. DOI: https://doi. org/10.1016/j.biocontrol.2009.05.008

Roy H., Pell J.K. 2000. Interactions between entomopathogenic fungi and other natural enemies: Implications for biological control. Biocontrol Science and Technology 10 (6): 737-752. DOI: http://dx.doi.org/10.1080/09583150020011708

Roy H., Steinkraus D.C., Eilinberg J., Hajek A.E., Pell J.K. 2006. Bizarre interactions and endgames: entomopathogenic fungi and their arthropod hosts. Annual Review of Entomology 51: 331-357.

Sarmento R.A., Pallini A., Venzon M., Fonseca de Souza F., Molina-Rugama A.J., Lima de Olivera C. 2007. Functional response of the predator Eriopis connexa (Coleoptera Coccinellidae) to different prey types. Brazilian Archives of Biology and Technology 50: 121-126.

Scorsetti A.C., Humber R.A., García J.J., López Lastra C.C. 2007. Natural occurrence of entomopathogenic fungi (Zygomycetes: Entomophthorales) of aphid (Hemiptera: Aphididae) pests of horticultural crops in Argentina. BioControl 52: 641-655. DOI 10.1007/s10526-006-9045-1

Scorsetti A.C., Maciá A., Steinkraus D.C., López Lastra C.C. 2010. Prevalence of Pandora neoaphidis (Zygomycetes: Entomophthorales) infecting Nasonovia ribisnigri (Hemiptera: Aphididae) on lettuce crops in Argentina. Biological Control 52: 46-50. DOI: https://doi.org/10.1016/j. biocontrol.2009.09.005

Scorsetti A.C., Pelizza S., Cabello M.N. 2012. New records of hypocrealean fungi infecting aphids and whiteflies: pathogenicity against Myzus persicae and interaction with its predator Eriopis connexa. Biocontrol Science and Technology 22 (9): 1099-1105. DOI: http://dx.doi.org/10.1080/095831 57.2012 .710320

Silva R.B., Cruz I., Zanuncio J.C., Figueiredo M.L.C., Canevari G.C., Pereira A.G., Serrão J.E. 2013. Biological aspects of Eriopis connexa (Germar) (Coleoptera: Coccinellidae) fed on different insect pests of maize (Zea mays L.) and sorghum [Sorghum bicolor L. (Moench.)]. Brazilian Journal of Biology 73 (2): 419-424. DOI: 10.1590/S1519-698420 13000200025

Simelane D.O., Steinkraus D.C., Kring T.J. 2008. Predation rate and development of septempunctata L. influenced by Neozygites fresenii-infected cotton aphid prey. Biological Control 44: 128-135. DOI: https://doi.org/10.1016/j. biocontrol.2007.10.004

Steenberg T., Harding S. 2009. Entomopathogenic fungi recorded from the harlequin ladybird, Harmonia axyridis. Journal of Invertebrate Pathology 102: 88-89. DOI: https://doi. org/10.1016/j.jip.2009.07.002

Toledo A.V., Remes Lenicov A.M.M., López Lastra C.C. 2008. Host range findings on Beauveria bassiana and Metarhizium anisopliae (Ascomycota: Hypocreales) in Argentina. Boletín de la Sociedad Argentina de Botánica 43 (3-4): 211-220. 